\title{
Cloud Computing and Information Technology Strategy
}

\author{
Antonio Mariano Carlos Junior', Cesar Augusto Biancolino², Emerson Antonio Maccari ${ }^{3}$
}

\begin{abstract}
Cloud computing represents a new paradigm that enables the utility computing model in which computing resources are offered and consumed as a service on demand, pay as you go, in a model similar to that of electricity. The objective of this work is to identify threats and opportunities of the cloud computing model and its influence on the strategy of companies that consume Information Technology. To do so, a survey was conducted with leading IT executives from 64 medium and large companies in Brazil. We noticed the influence of cloud computing in migrating the focus of the corporate IT departments to the management of services and contracts, resulting into the demand for professionals with IT analyst integrated and business profiles.
\end{abstract}

Keywords: cloud computing; utility computing; information technology; strategy.

'Hewlett-Packard Company - Av. Das Nações Unidas, I290I - 23o Andar - São Paulo, SP 04578-000 - Brasil. Phone: +55II55025000. E-mail: antonio.mariano@hp.com.

${ }^{2}$ Programa de Mestrado Profissional em Administração - Gestão em Sistemas de Saúde - Universidade Nove de Julho - UNINOVE Avenida Francisco Matarazzo, 6I2 - Bloco C - Io Andar - Água Fria - São Paulo, SP 0500I-I00 - Brasil. Phone: +55II3365932I. E-mail: biancolino@uninove.br.

${ }^{3}$ Programa de Pós Graduação em Administração - Universidade Nove de Julho - UNINOVE - Avenida Francisco Matarazzo, 612 - Bloco C - 2o Andar - Água Fria - São Paulo, SP 0500I-100 - Brasil.Phone: +55I I3365932 I. E-mail: maccari@uninove.br. 


\section{Introduction}

Information technology (IT) is part of the value chain and corporate strategy of companies (PORTER, 1998). This area has been highlighted by its rapid development being responsible for several technological innovations, which affect the strategic positioning of companies. In the 1970s the computing model based on both proprietary technology and high cost large computers, known as mainframes, contributed to the formation of oligopolies in companies providing IT services which provided data processing to consumer companies.

In the 1980s the emergence of the distributed computing technology, marked by the introduction of personal computers and networking and interoperable standard technologies, raised a number of new providers specialized in hardware and software which provided their products to consumer companies to build their own data processing centers (DPC). In the 1990s, the introduction of the Internet in the business environment, brought along a number of innovations, contributed to the acceleration of globalization and encouraged the emergence of new business models.

In this context, IT outsourcing was offered by providers and adopted by consumers as an alternative for companies to remain focused on their activities and reduce costs in order to support the production chain. In the first decade of this century, technological advances in areas such as connectivity, information storage technologies, computing power and information security, enabled the appearing of the Cloud Computing model, supposed to allow the rationalization of IT investments through the dynamic allocation of resources hired as a service. According to Carr (2008, p. 214), "Technology shapes the economy and economy shapes the society." New technologies bring new opportunities and new threats to businesses in several spheres. Recent examples in the area of information technology help illustrate this potential:

(a) In the general environment, consisting of elements of the wider society that affect their industries and enterprises (HITT, IRELAND, \& HOSKISSON, 2008), the technology segment, with the emergence of the Internet, had a strong influence on the world trade. This technology allowed the enhancement of existing business models, such as the emergence of e-Bay (Internet auction website), which established in a large scale, a platform to connect two fragmented groups of users: those wishing to sell and those who wanted to buy the most varied products (PORTER, 2008).

(b) In the environment of specific industries or sectors, consisting of a set of factors that may influence a company and its competitive actions and reactions (HITT, IRELAND,
\& HOSKISSON, 2008), technology has enhanced the threat of substitute products. The ecosystem iPod + iTunes (digital music player and online music store from Apple), have redefined the market for sales of music, based before on compact disks (CD). In this context, the cloud computing model enables a new paradigm for IT, the Utility Computing model, where IT starts being offered and consumed as a service, paid for its use in a fashion which is similar to the electricity segment. This new paradigm has the potential to change the relations between provider and consumer IT companies, influence the competitiveness of companies in various sectors as well as change the role of the IT professional in the organizations. Before such a broad potential, the raised question is: - Which are the current threats and opportunities of cloud computing model for IT consuming companies?

Reflecting the necessary adherence to the main issue of research, the objective of this research can be described as to identify threats and opportunities of the cloud computing model and its influence in a strategy of IT consumers company. The specific objectives arising can be grouped into three clusters: (a) Identify the influence of the model of cloud computing for business strategy consumer IT (Specific Objective I = SOI); (b) Identify opportunities and barriers to the adoption of the model (SO2) and (c) Identify the influence of the model on the role of the IT professional in organizations (SO3).

The article has the following structure. After this introduc $\neg$ tory section, the article presents the theoretical reference related to cloud computing, its definition, characteristics, service and implementation models. In the third section, presents the research method, which is characterized by being descriptive with the professionals responsible for the IT areas for companies in Brazil. The research results and its analysis are discussed in section 4. Finally, find 7 ings are presented in section 5 , which also discusses the results in light of the theoretical reference.

\section{Literature Review}

The information technology sector has presented a fast technological evolution in the past five decades. At the same time, business models have evolved among IT provider and consumer companies. The first decade of this century saw the rise of significant advances in several areas of information technology. The processing power breakthrough at low costs, foreseen in the Moore's Law, known due to Gordon Moore's assertion (1965), founder of Intel, according to which "the number of transistors embedded in a chip will double approximately every 24 months", has been demonstrated in the doubling of computing power every two years.

ISSN: 07 I8-2724. (http://www.jotmi.org)

Journal of Technology Management \& Innovation (c) Universidad Alberto Hurtado, Facultad de Economía y Negocios. 
At the same time, advances in the power of communication networks, foreseen in the Metcalfe's Law, known due to the Robert Metcalfe's statement (1995), inventor of the Ethernet networking technology, according to which "the value (or importance) of a telecommunications network is proportional to the square of the number of communications devices connected", has been demonstrated through the growth of the Internet, accelerated by new connectivity technologies such as fiber optics and wireless networks of the third and fourth generations, resulting in a scenario described as hyperconnectivity.

Another relevant phenomenon has been the adoption of the IT industry standards, enabling the interoperability among products from different manufacturers. The Ethernet network technologies (wired) and WiFi (wireless), the Internet communication protocol (TCP/IP), are examples of established and widely used standards. Added to this, there has been an important breakthrough in information security technologies propelled, among other factors, by the investments that have emerged since the terrorist attacks on September II, 200I in the USA.

These four combined factors: an increase in computing power at low costs, hyperconnectivity, standardization and advances in information security technology; created a scenario favorable to the emergence of the concept of cloud computing enabling the utility computing model, where computing resources are provided on demand by IT services providers to customers who pay as you go. Although the concept of utility computing was developed in the 60's by Douglas F. Parkhill apud (ARMBRUST, et al., 2009), only now with the technologies used in cloud computing it becomes feasible.

According to Petri (20I0, p. 13), "Cloud computing refers to the capabilities dynamic provisioning of IT (hardware, software or services) from third parties via the network." According to Simon (2010, p.18I4), "Cloud computing is a style of computing where massively scalable IT capabilities are provided as a service via the Internet to multiple customers." In this paper the definition of the National Institute of Standards and Technology (NIST) of the United States is adopted which is considered the most comprehensive by several authors (SIMON, 20I0) (PETRI, 20I0). According to Mell and Grance (20I0, p. I):

cloud computing is a model to enable convenient access on demand to a shared set of configurable computing resources (e.g.: networks, servers, storage, applications and services) that can be provisioned and released quickly with minimal management effort or interaction from the service provider.

This model promotes availability and consists of five essential features three service models and four deployment models. The Figure I illustrates the NIST framework for the cloud computing definition.

Some keywords in this definition reveal the essence of cloud computing: convenient access, on demand, shared set of computational resources, provisioned and released quickly, mini-

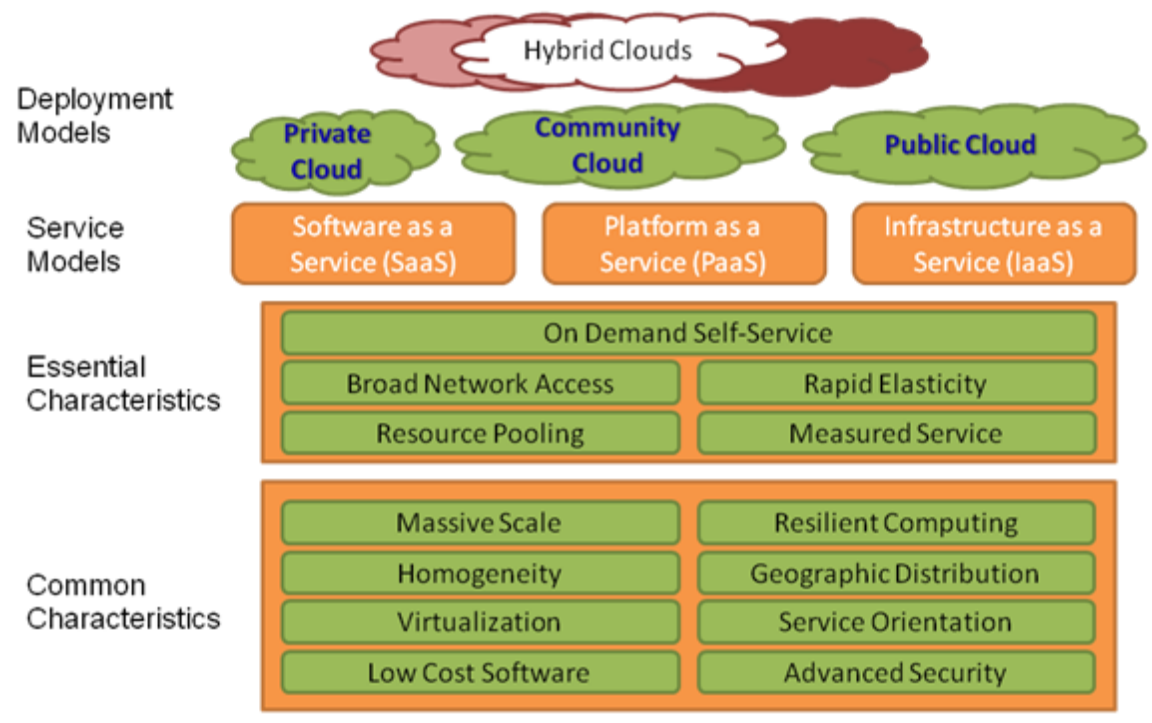

Figure I - Cloud computing framework.

Source:Tseronis, Lewin, Garbas and Mell (2010, p.15)

ISSN: 07 I8-2724. (http://www.jotmi.org)

Journal of Technology Management \& Innovation (c) Universidad Alberto Hurtado, Facultad de Economía y Negocios. 
mal management effort. The definition also refers to sets of essential features, implementation and service models which are listed below, based on the NIST settings and adapted to the business language. According to Mell and Grance (2010, p. I), there are five main cloud computing features:

- On demand self-service - the user ability in provisioning computing resources according to the business needs in an automated fashion without requiring any human interaction with the service provider;

- Broad network access - services are enabled via network - usually the Internet - and can be virtually accessed anywhere through different devices (computers, cell phones, tablets);

- Resources pooling - the computational resources of the service provider (computers, storage drives, network, softwares) are pooled and shared to attend multiple users (called multi-tenant model);

- $\quad$ Rapid elasticity - the service capabilities (processing, storage, access speed) can be rapidly provisioned and resiliently provided, in some cases automatically, to meet the increase or decrease of the users demand;
- $\quad$ Measured services - the use of computing resources can be monitored, controlled and measured in a transparent manner to both the service provider and the customer.

A survey to rank the benefits commonly attributed to the "cloud" was conducted by IDC with 263 IT executives in the third quarter of 2009.Table I presents the results of this survey.

The potential benefits of cloud computing constitute a central element in building a business case for adopting the model. These benefits can be grouped into two areas: (a) Finance economy of scale, resilience and cost reduction and (b) Strategic - flexibility, agility, risk sharing, reducing time to explore new business opportunities.

An analysis of these and other authors like Rohon (2009) and Petri (2010), allows grouping the challenges and barriers to cloud computing in four main areas: (a) Security; (b) Availability; (c) Performance and Scalability; (d) Standardization and Interoperability. In this context, the study of Armbrust et. al. (2009) identified the top 10 barriers and opportunities for the cloud computing growth, which are illustrated in table 2 .

\begin{tabular}{|l|l|}
\hline Pay only for what you use & $77,9 \%$ \\
\hline Easy / fast to deploy to end-users & $77,7 \%$ \\
\hline Monthly Payments & $75,3 \%$ \\
\hline Encourages standards systems & $68,5 \%$ \\
\hline Requires less in-house IT Staff, costs & $67 \%$ \\
\hline Always offers latest functionality & $64,6 \%$ \\
\hline Sharing systems with partners simpler & $63,9 \%$ \\
\hline Seems like the way of the future & $54 \%$ \\
\hline
\end{tabular}

Table I - Benefits commonly attributed to cloud computing. Note Source: IDC Executive Panel apud Gens (20I0)

\begin{tabular}{|l|l|l|}
\hline & Obstacle & Opportunity \\
\hline I & Availability of Service & $\begin{array}{l}\text { Use Multiple Cloud Providers to provide Business Continuity; Use Elasticity to De- } \\
\text { fend Against DDOS attacks }\end{array}$ \\
\hline 2 & Data Lock-In & Standardize APIs; Make compatible software available to enable Surge Computing \\
\hline 3 & Data confidentiality and Auditability & $\begin{array}{l}\text { Deploy Encryption,VLANs, and Firewalls;Accommodate National Laws via Geograph- } \\
\text { ical Data Storage }\end{array}$ \\
\hline 4 & Data transfer Bottlenecks & $\begin{array}{l}\text { FedExing Disks; Data Backup/Archival; Lower WAN Router Costs; Higher Bandwidth } \\
\text { LAN Switches }\end{array}$ \\
\hline 5 & Performance Unpredictability & $\begin{array}{l}\text { Improved Virtual Machine Support; Flash Memory; Gang Scheduling VMs for HPC } \\
\text { apps. }\end{array}$ \\
\hline 6 & Scalable Storage & Invent Scalable Store \\
\hline 7 & Bugs in Large Scale Distributed Systems & Invent Debugger that relies on Distributed VMs \\
\hline 8 & Scaling Quickly & $\begin{array}{l}\text { Invent Auto-Scaler that relies on Machine Learning; Snapshots to encourage Cloud } \\
\text { Computing Conservationism }\end{array}$ \\
\hline 9 & Reputation Fate Sharing & Offer reputation-guarding services like those for email \\
\hline 10 & Software Licensing & Pay-for-use licenses; Bulk use sales \\
\hline
\end{tabular}

Table 2: Quick preview of top 10 obstacles to and opportunities for growth of cloud computing. Note. Source:Armbrust et al (2009, p. I4).

ISSN: 07 I8-2724. (http://www.jotmi.org)

Journal of Technology Management \& Innovation (c) Universidad Alberto Hurtado, Facultad de Economía y Negocios. 
An important aspect of IT strategy for cloud computing is to ensure the possibility of migrating from one service provider to another when necessary. This migration may be motivated by factors such as higher quality, lower costs, mergers and acquisitions (of consumer or provider companies), expanding the services scope and providers rationalization. The barrier in this case is the lack of standardization among cloud computing providers allowing migration and interoperability of services. This can pose a migration barrier for the cloud services user companies, which may be "tied" to a single provider. Moreover, the lack of standardization can make it difficult for the user company to resume to the traditional model after having migrated to the cloud.

Another factor to consider is the fact that the user company usually will have a mixed model, which consists of traditional IT services implemented internally and hired cloud services. The standardization of interfaces between these services is important to enable interoperability and integration among them. An evolution in this area is required for the adoption of cloud computing on a large scale, however several standardizing efforts are ongoing, led by several entities such as: CloudAudit, National Institute of Standards and Technology (NIST), Open Cloud Manifesto, Distributed Management Task Force (DMTF), The European Telecommunications Standards Institute (ETSI), Open Grid Forum (OGF), Object Management Group (OMG), Open Cloud Consortium (OCC), Storage Networking Industry Association (SNIA), The Open Group, Association for Retail Technology Standards (ARTS) and TM Forum. (Cloud Standards, 2010)

The process of migration to the cloud computing model represents a significant change for the IT staff of the company. The process should be conducted carefully and followed by a professional development program aiming at their adapting to the new scenario Rothon (2009). With the utility computing model, the IT department should start focusing on the interaction among different areas of the business acting as an internal consultant acting on business processes improvement and optimization. The Chief of Information Officer $(\mathrm{ClO})$ and his team should position themselves as strategic business partners Simon (2010). This is the focus of this research, to understand how IT executives and their staff positioned themselves as strategists against the cloud computing technology, identifying which are the current threats and opportunities of cloud computing model for their companies.

\section{Methodology}

\section{Research Design}

This research is descriptive, since it aims to identify threats, opportunities and influences the type of the cloud computing model, from the perspective of executives responsible for IT areas of companies in Brazil. According to Medeiros (2009, p. 30), the descriptive research is composed of "facts study, analysis, reporting and interpretation of the physical world without any interference from the researcher, e.g.: market and opinion surveys". For Gil $(2010$, p. 28$)$, the researches that "aim to raise opinions, attitudes and beliefs of a population", are included in the descriptive research group.

This research method will be the field survey and the survey instrument will be a structured questionnaire. According to Gil (2010, p. 35), the surveys "are characterized by direct questioning people whose behavior is wished to know. Basically, it proceeds in order to request information from a significant group of people around the problem studied and then, through a quantitative analysis, obtain the conclusions regarding the collected data".

The main advantages of the questionnaire are: direct knowledge of reality, economy, agility and quantification (Gil, 20l0). For Gil (2010, p. 103), "the questionnaire is the quickest and cheapest way to obtain information, in addition to not requiring staff training also ensuring anonymity." According to Kotler and Keller (2006, p. 103), "questionnaires should be developed, tested and enhanced very carefully before being applied in large scale." For Gil (2010, p. 99), the survey phases are, sequentially: Goal specifications; Concepts and variables operationalization; Data collection instrument preparation; Instrument pre-test; Sample selection; Data collection and verification; Data analysis and interpretation; Report Essay.

\section{Data Collection Procedure}

The preparation of the questionnaire used as a research tool for primary data collection followed the following schedule: (a) Preparation of questions and pilot survey instrument pre-test with five IT professionals and (b) Preparation and application of the definitive survey instrument which presents the relation among the specific proposed objectives and the construct validity of the research. The table 3 illustrates the construct.

The final questionnaire was prepared with a set of seven open questions being one of the dichotomous kind, with two possible answers and six of multiple choice, with three or more possible answers. An open question completely unstructured was also included. The questions were prepared

ISSN: 07 I8-2724. (http://www.jotmi.org)

Journal of Technology Management \& Innovation (c) Universidad Alberto Hurtado, Facultad de Economía y Negocios. 
in order to be clear, precise and objective. In multiple choice questions, responses used in international research used as secondary data were used, as well as the option "others" where an additional response could be included. The layout was developed to be restricted to one page containing both the cover letter and the questions.

In order to work with a sample of all IT consumer companies in Brazil a high investment is necessary and possibly the goal of this study will not be achieved within the appropriate time limits. On the other hand, the cloud computing technology is recent and possibly not well known by consumer companies.Aiming to exploit a universe of companies which are enlightened and engaged in discussions about new technologies, a set of companies whose heads of the IT departments are part of organizations and discussion forums of IT, will be worked on.

For practical purposes, the IT4CIO, entity which gathers executives responsible for the IT areas of companies in Brazil (ClOs) and also sponsors forums, events and research, was chosen. The universe of private companies which is part of the organization was selected, specifically the $\mathrm{ClO}$ Brazil forum participants with its 2010 edition held from September 22nd - 26th, attended by 102 companies, represented by their main IT executives. 102 questionnaires were distributed over the sessions of the $\mathrm{ClO}$ Brazil 2010 event. There was no clarification of any respondent eventual doubts. The executives were supposed to respond and return them by the end of the event. At the end of the event 64 questionnaires were collected, $62 \%$ of the distributed total.

\section{Procedure and Data Analysis}

The data analysis is divided into three clusters, aligned with the research specific aims:

(a) Cloud computing influence on IT strategy - This cluster consisted of five questions, being three multiple choice, one (I) dichotomous and one (I) open question. The first two questions were aimed at identifying the familiarity with the concept of cloud computing and its use in the company IT strategy. The following three questions aimed at identifying business requirements met, the adoption of process maturity and intended advantages with cloud computing. Initially there was a quality analysis of the sample data in order to rule out the questionnaires that presented null answers for the questions of this cluster. 9 (or 14\%) of 64 questionnaires were discarded, resulting in a base of 55 valid questionnaires for the analysis of this cluster, equivalent to $86 \%$ of the received questionnaires;

(b) Barriers and opportunities for the cloud computing adoption - this cluster was composed of one (I) multiple choice question.At first there was a quality analysis of the sample data in order to rule out the questionnaires that presented null answers for the questions of this cluster. I (or 2\%) of 64 questionnaires was discarded, resulting in a base of 63 valid questionnaires for the analysis of this cluster, equivalent to $98 \%$ of the received questionnaires.

(c) IT Professional influence on organizations - this cluster was made of two multiple choice questions. Again there was a quality analysis of the sample data in order to rule out the questionnaires that presented null answers for the questions of this cluster. 7 (or I 1\%) of 64 questionnaires were discarded, resulting in a base of 57 valid questionnaires for analysis, equivalent to $89 \%$ of the received questionnaires.

After examining the data quality, the response analysis of the questionnaires considered valid in each cluster was initiated.

\section{Obtained Results}

The sample used in the research is composed of 64 questionnaires, being two of them anonymous. The companies are medium or large, national and multinational. The questionnaires were filled out by these companies' top IT executives in Brazil. The following illustrations feature these companies and their respondent professionals.

\begin{tabular}{|l|l|l|}
\hline $\begin{array}{l}\text { Reference } \\
\text { (Data Collection) }\end{array}$ & Research Objectives & Variables \\
\hline I & SOI & Familiarity with Cloud Computing (CC) \\
\hline 2 & SOI & Use of CC \\
\hline 3 & SOI & Strategic Requirements serviced by CC \\
\hline 4 & SOI & Stage of Adoption of CC \\
\hline 5 & SOI & Advantages and Benefits sought with CC \\
\hline 6 & SO2 & Identifying Barriers to adoption of CC \\
\hline 7 & SO3 & Influence of CC in the role of IT \\
\hline 8 & SO3 & Influence of CC in the profile of the IT professional \\
\hline
\end{tabular}

Table 3 - Construct validity related to the data collection instrument to the survey specific goals

ISSN: 07 I8-2724. (http://www.jotmi.org)

Journal of Technology Management \& Innovation (c) Universidad Alberto Hurtado, Facultad de Economía y Negocios. 
The table 4 features the revenue of 43 out of the 64 respondent companies. Data extracted from Maiores e Melhores (Largest and Best) at the Exame.com magazine website.

\begin{tabular}{|l|l|}
\hline REVENUE & USD (MILLIONS) \\
\hline AVERAGE & 974 \\
\hline MODE & 422 \\
\hline MEDIAN & 662 \\
\hline MINIMUM & 194 \\
\hline MAXIMUM & 7394 \\
\hline
\end{tabular}

Table 4 - Respondent companies revenue in 2009. Note. Source: (EXAME, 2009)

The table 5 features the number of employees of 41 out of the 64 respondent companies. Data extracted from Maiores e Melhores (Largest and Best) at the Exame.com magazine website.

\begin{tabular}{|l|l|}
\hline EMPLOYEES & $\mathbf{N}$ \\
\hline AVERAGE & 3173 \\
\hline MINIMUM & 293 \\
\hline MAXIMUM & 16375 \\
\hline
\end{tabular}

Table 5 - Respondent companies number of employees in 2009. Note. Source: (EXAME, 2009)

The table 6 features the operation time of 47 out of the 64 respondents companies. Data extracted from the respondent companies websites.

\begin{tabular}{|l|l|}
\hline OPERATION TIME & YEARS \\
\hline AVERAGE & 49 \\
\hline MINIMUM & 5 \\
\hline MAXIMUM & 175 \\
\hline
\end{tabular}

Table 6 - Respondent companies operation time. Note. Source: Respondent companies websites

The table 7 features the national or multinational scope of 62 out of the 64 respondent companies. Data extracted from the respondent companies' websites.

\begin{tabular}{|l|l|}
\hline MULTINATIONAL & $37 \%$ \\
\hline NATIONAL & $63 \%$ \\
\hline
\end{tabular}

Table 7 - Respondent companies scope. Note. Source: Respondent companies' websites
The table 8 features distribution of positions of 62 out of the 64 respondents. Data extracted from IT4CIO.

\begin{tabular}{|l|l|}
\hline $\mathrm{ClO}$ & $26 \%$ \\
\hline Director & $8 \%$ \\
\hline Manager & $58 \%$ \\
\hline Coordinator & $8 \%$ \\
\hline
\end{tabular}

Table 8 - Respondents' positions. Note. Source: IT4CIO

As follows, the quantitative research results will be presented in the light of the theoretical reference, making an application between the main concepts and the study findings.

\section{Influence on Companies Strategy}

Executive familiarity with cloud computing.

The table 9 illustrates the answers to the question: - Are you familiarized with the cloud computing concept?

\begin{tabular}{|l|l|}
\hline More Flexibility & $32 \%$ \\
\hline Costs Reduction & $26 \%$ \\
\hline Greater Agility & $16 \%$ \\
\hline Others & $2 \%$ \\
\hline
\end{tabular}

Table 9 - Familiarity with the cloud computing concept

It was observed that in a universe of 55 valid respondents, $51 \%$ of the executives state being partially familiar with the cloud computing concept while $49 \%$ state being fully familiar with the cloud computing concept. It not possible to have conclusions on the understanding of cloud computing based solely on this question by the difficulty of judging the level of knowledge on the subject however, considering, as noted in the theoretical reference research, the concept of cloud computing is recent and still evolving, the percentage of $49 \%$ of the executives stating a total familiarity with the topic demonstrates the strong interest of managers and relevance of the topic.

\section{Cloud computing use in the company IT strategy}

The Table 10 illustrates the answers to the question: - Does your company IT strategy makes use of cloud computing?

\begin{tabular}{|l|l|}
\hline Yes & $38 \%$ \\
\hline No & $62 \%$ \\
\hline
\end{tabular}

Table 10 - Cloud computing use in the IT strategy

It was observed that $62 \%$ of the 55 valid respondent companies do not use cloud computing in their IT strategy, while $38 \%$ claim to use cloud computing in their IT strategy. Study-

ISSN: 07 I8-2724. (http://www.jotmi.org) 
ing the correlation with the previous question, it is observed that $57 \%$ of the companies whose IT executives state being fully familiarized with cloud computing, make use of this technology in their IT strategy, while $32 \%$ of the companies whose IT executives state being partially familiarized with cloud computing, make use of this technology in their IT strategy. The highest correlation among companies that make use of cloud computing and their IT executives familiarity with the concept can be given by two scenarios: companies work with cloud computing once their $\mathrm{ClOs}$ know the concept or ClOs know the concept once their companies work with cloud computing.

Business strategy requirements which led to the model adoption

The table I I illustrates the answers to the question: - Which business strategy requirements led to the cloud computing adoption?

\begin{tabular}{|l|l|l|l|}
\hline Costs & $25 \%$ & Focus on Business & $4 \%$ \\
\hline Performance & $21 \%$ & Mandatory & $4 \%$ \\
\hline Elasticity & $18 \%$ & Management & $4 \%$ \\
\hline Availability & $11 \%$ & Flexibility & $4 \%$ \\
\hline Security & $7 \%$ & Service & $4 \%$ \\
\hline
\end{tabular}

Table II - Business strategy requirements that led to the cloud computing adoption

This open question was designed to identify the connection between business requirements and possible features of the cloud computing model. It was observed that 21 out of the 55 valid respondent companies, equivalent to $31 \%$, identified business strategy requirements that led to the cloud computing model adoption. The predominant requirements identified for the adoption of cloud computing were: cost reduction, performance, resilience, availability and security. The set of responses observed is consistent with the theoretical framework researched. It can be noted, however, the presence of an interesting requirement highlighted by one of the respondents who identified as mandatory the use of cloud computing in the automotive sector. The correlation of answers to this question with the previous one resulted in $80 \%$ of the companies that already use cloud computing were able to identify the business strategy requirements which led to the adoption of technology.
Phase of Adoption process which the company is in

The table 12 illustrates the answers to the question: Which phase of this technology adoption process your company is in?

\begin{tabular}{|l|l|}
\hline Production & $11 \%$ \\
\hline Implementation & $16 \%$ \\
\hline Planning & $73 \%$ \\
\hline
\end{tabular}

Table 12 - Phase of the cloud computing adoption process which the company is in

It was observed that $73 \%$ of the 55 valid respondent companies are in the planning phase of the cloud computing adoption, while $16 \%$ are in the implementation phase and $11 \%$ are in the production phase.

\section{Advantages and benefits targeted with cloud computing}

The table 13 illustrates the answers to the question: - What advantages and benefits does your company target with the adoption of this model?

\begin{tabular}{|l|l|}
\hline Unknown & - \\
\hline Yes, partially & $51 \%$ \\
\hline Yes, totally & $49 \%$ \\
\hline
\end{tabular}

Table I3 - Advantages and benefits targeted with cloud comput-

ing

It was observed that "more flexibility" was the most targeted benefit with the adoption of cloud computing, followed by "cost reduction" and "greater agility." This observation is consistent with the theoretical framework although there was more emphasis on the model flexibility than the one found in IDC's research in the U.S.

\section{Barriers to adoption and opportunities}

\section{Barriers to adoption of the cloud computing model}

Table 14 illustrates the answers to the multiple choice question: - In your opinion, what are the main adoption barriers for the cloud computing model by the companies in your segment?

\begin{tabular}{|l|l|}
\hline More Flexibility & $32 \%$ \\
\hline Costs Reduction & $26 \%$ \\
\hline Greater Agility & $16 \%$ \\
\hline Others & $2 \%$ \\
\hline
\end{tabular}

Table 14 - Cloud computing adoption barriers

ISSN: 07 I 8-2724. (http://www.jotmi.org) 
It was observed that among the 63 valid respondent companies, the main barriers to the cloud computing adoption are, in order of frequency: security, availability, performance and standardization. The order of the factors was identical to those found in international researches. Other barriers identified by the respondents, being three related to applications: use of considerably customized applications, integration with other applications and strategic software provider has no solutions. Two of them are related to governance: lack of governance and secrecy. Finally, the lack of knowledge on the subject was identified as a barrier for adoption. It can be identified that, beyond the concern with technical factors intrinsic to the cloud computing technology (security, availability and performance), the limitations of the business applications existing today, not yet adapted to the cloud computing model, and the lack of knowledge on the subject are barriers for its adoption, creating opportunities to be exploited by the application and solutions providers through knowledge dissemination and applications adaptation.

\section{Influence on the IT Role}

\section{IT roles emphasized due to cloud computing}

The table 15 illustrates the answers to the question: which IT area roles were emphasized in your company due to cloud computing?

\begin{tabular}{|l|l|}
\hline Service Management & $36 \%$ \\
\hline Supply Chain Management & $22 \%$ \\
\hline Performance Management & $16 \%$ \\
\hline Others & $4 \%$ \\
\hline
\end{tabular}

Table I5 - IT roles emphasized due to cloud computing

It was observed that at the 57 valid respondent companies, the IT roles emphasized due to the cloud computing model were, in order of frequency: service management, supply chain management and performance management. Other roles identified in the research: safety and delivery of standardized services management. The responses observed are consistent with the paradigm shift promoted by the utility computing model provided as a service. In this model, the IT area of the consumer companies is now a manager of standardized services from several providers and administered by contracts with specific performance levels (Service Level Agreements - SLAs).
New IT professional profile due to cloud computing

The table 16 illustrates the answers to the question: - What are the new IT professional profiles necessary for the organization due to the emergence of the cloud computing model?

\begin{tabular}{|l|l|}
\hline Integrated: IT and Business Analyst & 50 \\
\hline Specialist: Design and Services Management & 12 \\
\hline Others & 3 \\
\hline
\end{tabular}

Table 16 - New IT Professional profiles due to cloud computing

It was observed that the 57 valid respondents companies identified more often the integrated profile of the IT and business analyst as necessary due to the emergence of cloud computing. The design and services management integrated professional profile had lower frequency. Among other roles identified in the study are the contract manager and services specialist. These data point to the need for training programs to these professionals emphasizing business management, services and contracts knowledge and skills, besides knowledge and skills in technology. This is an opportunity to be exploited by professional training institutions.

\section{Discussion}

Cloud computing represents a new technical and business paradigm, with the potential to enable the utility computing model and transform relations between IT consumer and provider companies. The findings of this study aim to contribute for the strategic preparation and positioning of IT consumer companies before this new paradigm.

Regarding the general objective of the research, which was to identify threats and opportunities of the cloud computing model and its influence on the IT consumer companies' strategy, one can conclude that there are opportunities to reduce costs and increase agility provided by the adoption model, which has influenced consumer companies to include cloud computing in its strategic agenda. Progresses in areas such as security, performance, availability and standardization are still needed to accelerate the adoption of the model, according to Armbrust et al (2009).

Relatively for the specific purpose of identifying the influence of the cloud computing model on the IT consumer companies' strategy, it can be noticed that there is a strong interest in the subject aiming to obtain cost savings, improved performance and resilience of computing resources, thus providing, greater agility and flexibility to meet the business strategy demands. This point was discussed for Petri (20I0) and Mell and Grance (2010). 
As for the goal of identifying barriers and opportunities to adopt the model, the survey showed that concerns about security, availability, performance, standardization, adaptation of applications and governance are barriers for the cloud computing adoption. So there are clear opportunities for improvement and differentiation of provider companies in these aspects. Moreover, regulators and standardization institutions should focus on the rapid evolution of standards, rules and regulations related to cloud computing.

And finally, regarding the identification of the model influence on the IT professional role in organizations, it was noticed that in the new utility computing paradigm, the IT area in the consumer companies starts focusing on management of the cloud computing providers hired services in order to optimize business processes. In this scenario, there is an emphasis of the IT department in services, supply chain and performance management. As a result, the professionals should have an integrated profile of IT business analyst. There are therefore opportunities to adapt the training programs of these professionals, which should emphasize on business management, services and contracts knowledge and skill, besides the knowledge in technology.

\section{Research Limitations}

According to Gil (2010), among the main survey limitations are: (a) Perspective aspects emphasis - the surveys collected data regarding the people's perception, which is subjective and may result in distorted data; (b) Limited apprehension of the change process - The survey provides a static view of the phenomenon under study, indicating no variation trends or possible structural changes. (c) Another limitation of this research refers to the selected sample, once it represents a limited group of IT executives who for their commitment to organizations and technology discussion forums, possibly present a higher degree of familiarity than the average concerning cloud computing technology and Finally (d) the questionnaire application was given through distribution.

When the approach is personal, the interviewer can clarify the questions to the interviewee, however when the questionnaires are distributed, the respondent might have doubts that if not clarified, may compromise the quality of the collected data.The limitations of this study are inherent in information surveys, such as an emphasis on perceptive aspects and limited understanding of the change process, and application of a questionnaire by means of distribution, where the existence of unanswered questions can compromise the quality of the data collected. Besides these, another limitation relates to the selected sample, representing a group of executives engaged in entities and discussion forums and therefore possibly having a greater degree of familiarity than the average with the cloud computing technology.

\section{References}

ARMBRUST, M., Fox, A., Griffith, R., Joseph, A. D., Katz, R., Konwinski, A., et al. (2009). Above the Clouds: A Berkeley View of Cloud Computing. University of California, Berkeley. http:// www.eecs.berkeley.edu/Pubs/TechRpts/2009/EE CS2009-28.pdf. [Accessed September,42010].

CARR, N. (2008). The Big Switch: Rewiring the World, from Edison to Google (I st Kindle ed.). Norton \& Company, New York. Cloud Standards. (2010, 24-8).

CLOUD STANDARDS. http://cloud-standards.org/wiki/index.php?title=Main_Page [Accessed September 19, 20I0].

EXAME: revista quinzenal de negócios. Ed. Abril. Maiores e Melhores 2009. http://mm.portalexame.abril.com.br. [Accessed October 12, 2010.]

GIL,A. C. (20I0). Como elaborar projetos de pesquisa.Atlas, São Paulo.

HITT, M.A., Ireland, R. D., \& Hoskisson. (2008).Administração Estratégica: competitividade e globalização (2 ed.). Cengage Learning, São Paulo.

IT4CIO. http://www.it4cio.com/portallT4CIO/index. php?lang=pt. [Accessed September II, 20I0]

LEE, K. K. (2005). Building Resilient IP Networks. Cisco Press, Indianapolis.

MEDEIROS, J. B. (2009). Redação Científica. Atlas, São Paulo.

MELL, P., Grance, T.The NIST Definition of Cloud Computing. National Institute of Standards and Technology. http:// csrc.nist.gov/groups/SNS/cloud-computing/cloud-def-vI 5 . doc [Accessed September 14, 20I0].

PETRI, G. (20I0). Shedding Light on Cloud Computing. CA Technologies IT Management Software and Solutions. http://www.ca.com/files/whitepapers/mpe_cloud_primer_0I10_226890.pdf [Accessed October 23, 2010].

PORTER, M. E. (1998). Competitive Advantage: creating and sustaining superior performance: with a new Introduction (Ist Kindle ed.). Free Press, New York.

ROTHON, J. (2009) Cloud Computing Explained: Implementation Handbook for Enterprises (2 Kindle ed.). Recursive Press, London.

SIMON, P. (2010). The next wave of technologies: opportunities from chaos. (Ist Kindle ed.). John Wiley \& Sons, New Jersey.

ISSN: 07 I8-2724. (http://www.jotmi.org) 
TSERONIS, P., Lewin, K., Garbas, K., \& Mell, P. (20I0). Federal Risk and Authorization Management Program (FedRAMP). National Institute of Standards and Technology. http://csrc. nist.gov/groups/SNS/cloud-computing/forum-workshop_ may20I0.html [Accessed September 4, 20I0]. 